\title{
Takım ve Bireysel Sporlarla Uğraşan Sporcuların Empatik Eğilim Puanlarının Karşılaş̦tırılması*
}

\author{
Sema Fidel ASLAN ${ }^{* *}$ \\ Hakkı ÇOKNAZ ${ }^{* * *}$
}

\section{Öz}

Bolu ilinde takım sporlarıyla ve bireysel sporlarla uğraşan sporcular üzerinde yürütülen bu çalışmanın amacı, spor branşlarının sporcuların empatik eğilimleri üzerindeki etkisini belirlemektir.

$\mathrm{Bu}$ amaçla Bolu ilinde takım sporuyla uğraşan 50, bireysel sporlarla uğraşan 51 sporcu olmak üzere toplam 101 sporcu araştırmanın örneklemini oluşturmaktadır. Araştırma sırasında sporcuların empatik eğilimlerini ölçmek için Dökmen (1988) tarafından geliştirilen "Empatik Eğilim Ölçeği” kullanılmıştır. Araştırmada ölçek yoluyla toplanan verilerin analizi ve yorumunda bilgisayar ortamı kullanılmıştır. Sporcuların empatik eğilimleri aritmetik ortalamalar $(\overline{\mathrm{x}})$ ve standart sapmalar (ss) kullanılarak betimlenmiştir. Verilerin dağılımının normal olmaması durumunda gurupların karşılaştırılmasında Mann-Whitney U testi, dağılımın normal olduğu durumda İndependent - samples-T Testi grupların karşılaştırılmasında kullanılmıştır. Anlamlılık düzeyi çalışma öncesi $\mathrm{p}<0.05$ olarak belirlenmiştir.

Yapılan istatistiksel değerlendirmede, takım ve bireysel sporlarla uğraşan kadınların empatik eğilim puanları arasında $(\mathrm{p}<0.05)$, takım sporlarıyla uğraşan kadın ve erkek sporcuların empatik eğilim puanları arasında $(\mathrm{p}<0.05)$, sporcuların milli olup olmaması durumuna göre $(\mathrm{p}<0.0)$ istatistiksel bir fark bulunmuştur. Diğer parametrelerin karşılaştırılmasında istatistiksel bir fark bulunmamıştır.

Bu bulgular sonucunda, kadınlarda takım ve bireysel sporlarla uğraşmanın empati eğilim puanlarını etkilediği, takım sporlarının da her iki cinsiyette empati eğilim puanlarını etkili olduğu söylenebilir.

Anahtar kelimeler: Spor, Empati, Bireysel spor, Takım Sporu

\footnotetext{
* 7. Ulusal Spor Bilimleri Öğrenci Kongresi’nde poster olarak sunulmuştur.

** Yüksek Lisans, A.İ.B.Ü. Beden Eğitimi ve Spor Yüksekokulu, sfaslan@gmail.com

*** Doç. Dr., A.İ.B.Ü. Beden Eğitimi ve Spor Yüksekokulu, coknaz_h@ibu.edu.tr
} 


\title{
Comparision of Emphatic Tendency Scores of the Athletes Exercising Team and Individual Sports****
}

\begin{abstract}
The aim of this study about athletes exercising team and individual sports in Bolu is to state the influence of sport branches on emphatic tendencies of athletes.

50 athletes exercising team sports and 51 athletes exercising individual sports, in total 101 athletes, in Bolu compose the research sample. In order to measure emphatic tendencies of the athletes "Emphatic Tendency Scale", developed by Dökmen (1988), is used in the research. Computer environment is used for the analysis and interpretation of the data gathered via scale in the research. Emphatic tendencies of the athletes are described by using arithmetic means $(\overline{\mathrm{x}})$ and standard deviations (ss). When the data distribution is not normal, Mann-Whitney $U$ tests are used in group comparisons, and when the distribution is normal Independent- Samples T Test is used in group comparisons. Significance level is determined as $\mathrm{p}<0.05$ before the research.

Statistical evaluation has revealed that there is a statistical difference between the emphatic tendency scores of women exercising team and individual sports $(\mathrm{p}<0.05)$ and the emphatic tendency scores of sportsmen and sportswomen exercising team sports $(\mathrm{p}<0.05)$ depending on whether they are national athletes or not. In comparison of other parameters no statistical difference has been found.

As a result of these findings, it can be said that exercising team and individual sports affect empathy tendency scores of women, and that team sports are influential on empathy tendency scores of both genders.
\end{abstract}

Keywords: Sports, Empathy, Individual sport, Team sports

\section{GíRiş}

İnsanı anlamak, psikolojinin en önemli konusudur. Bunun için de psikoloji insanın davranışlarına etki eden faktörleri ele alır ve inceler (Çetin, 2010). İnsan davranışlarına etki eden faktörlerden belki de en önemlisi grupla öğrenimdir. Günümüzde iletişim problemlerinin çözümünde bir etken olarak empatik davranış tavsiye ediliyor. Empati karşıdaki varlığı anlamaya yönelik bir iletişim şeklidir. $\mathrm{Bu}$, insan için kaçınılmaz olan iletişimi, sağlıklı bir şekilde sürdürebilmek açısından olmazsa olmazlardandır. Empatik davranışın en önemli özelliği bencillikten uzak olmasıdır (Çetin, 2010).

Empati konusunda yapılan araştırmalarda, farklı etnik gruplara hoşgörü gösteren bireylerin empati düzeylerinin yüksek olduğu, empatik beceriye sahip bireylerin kendi davranışlarının

$* * * *$ It was presented as poster in $7^{\text {th }}$ National Sports Sciences Student Congress. 
nedenlerini olduğu kadar, başkalarının davranışlarının nedenlerini anlamakta da daha başarılı oldukları, empatik becerileri yüksek olan bireylerin daha fazla prososyal davranış özelliklerini gösterdikleri, saldırganlığın temel yapıları ile empati arasında negatif bir ilişki olduğu, insanla çalışan meslek üyelerinin empati yeteneklerinin bireysel farklılıkları anlamalarına yardımcı olduğu, bilişsel ve duygusal empati ile kişilik özellikleri arasında yakın ilişki olduğu, insanlarla doğrudan ilişkileri olan ve mesleki eğitimleri sırasında karşısındaki kişinin rolünü alabilmeyi başarabilmiş profesyonellerin diğerlerine oranla empatik becerileri daha yüksek bulunmuştur (Berger,1984: Bayam ve ark. 1993; Yllmaz, Akyel, 2008 ). Sporculuğun da profesyonel bir iş oldu düşünülürse, sporcuların yapmış oldukları antrenmanların da sporcuların, insanların, empatik becerilerini geliştirdiği düşünülmektedir.

Spor sözcüğü Latince'de dağıtmak, birbirinden ayırmak anlamına gelen 'Disporte’ ve 'Deportone' sözcüklerinden kaynaklanır. Bu sözcük, İngilizce'de önceleri 'Disport' ya da 'Desport' biçiminde yer almış, zamanla ilk hecelerin aşınması sonucu tek heceli 'sport' sözcügüne dönüşmüştür (Yıldız, 1979). Sporun insan gelişiminin birçok alanına etkisi vardır. Ahlak ve empatinin bu alanlardan iki tanesi olduğu söylenebilir.

Spor ahlakı ve empati üzerine yapılan araştırmalar günümüze kadar çeşitlenerek artmıştır. Sporda ve günlük hayatta ahlaki yargı, saldırganlık (Bredemeier ve ark.1986; Bredemeier, 1994; akt: Balçıkanlı, Yıldıran, 2011), spor yapan ve yapmayan kişilerdeki ahlaki gelişim (Bredemeier ve Shields1986; akt: Balçıkanlı, Yıldıran, 2011), sporda antisosyal ve prososyal davranışlar (Kavussanu ve akd., 2006; Kavussanu, 2006; akt: Balçıkanlı,Yıldıran, 2011), sporda ahlaki akıl yürütme ve ahlaki davranış (Jones ve Mcnamee, 2000; akt: Balçıkanlı,Yıldıran, 2011), motivasyonel iklim ve sportmenlik (Lemyre ve Roberts,2002; Stornes ve Ommundsen, 2004; Gano-Overway ve ark. 2005; akt: Balçıkanlı,Yıldıran, 2011), sportmenlik yönelimi (Vallerand ve ark. 1997; Akt: Balçıkanlı,Yıldıran, 2011) ile ilgili araştırmalar spor ahlakına farklı bakış açıları getirmektedir. Literatürde empati çalışmaları da farklı boyutlardan ele alınmaktadır. Bazı araştırmacılar empatinin bilişsel yönüne vurgu yaparken (Eisenberg ve ark. 1998; akt: Balçıkanlı,Yıldıran, 2011), diğerleri duyuşsal yanın üzerinde durmaktadır (Mehrabian ve Epstein, 1972; akt: Balçıkanlı,Yıldıran, 2011). Ancak çoğunluğunun üzerinde durduğu ortak nokta, empatinin çok boyutlu bir yapısının olduğudur (Davis, 1980; Davis, 1983; Hoffman, 1990; Eisenberg ve Miller, 1987; akt: Balçıkanlı,Yıldıran, 2011). Sporda ahlaki ikilem yaratan durumlarla çok sık karşılaşılmaktadır. Ne yazık ki, spor ortamında karşılaşılan bu tip ikilem durumlarında sporcuların seçimi daha çok sportmenlik dışı davranışlardan yana olmaktadır. Bu durum özellikle profesyonel düzeydeki yakın temaslı takım sporlarında yaşanmaktadır. Spor branşları açısından genel bir durum değerlendirilmesi yapıldığında ise sportmenlik dışı davranışların gerçekleştiği görülmektedir (Bredemeier, 1994; Kavussanu ve ark. 2009; akt: Balçıkanlı, Yıldıran, 2011).

$\mathrm{Bu}$ araştırmada, sporcular arasında ilişkilerde bulunması gereken koşullar ve temel ilkeler içinde ilk sırada yer alan "empati” üzerinde durulmuştur ve spor branşları arasındaki farkın sporcuların empatik eğilim puanları üzerinde etkisi olup olmadığını ortaya koymak amaçlanmıştır. 


\section{YÖNTEM}

Bu bölümde araştırma grubu, veri toplama teknikleri, araştırma tekniği ve uygulanan istatistik yöntem hakkında bilgi verilmiştir.

\section{Evren ve Örneklem}

Bu çalışmanın evrenini Bolu’da takım ve bireysel sporla uğraşan 140 sporcu; örneklemini ise 50 takım sporuyla, 51 bireysel sporla uğraşan toplam 101 sporcu oluşturmaktadır.

\section{Veri Toplama Aracı}

Dökmen (1988) tarafından empatinin teorik özünden yola çıkarak geliştirilen Empatik Eğilim Ölçeği’nin amacı, kişilerin günlük yaşamında empati kurma potansiyellerini (eğilimlerini) ölçmektir. Likert türü bir ölçek olarak hazırlanan ve 20 maddeden oluşan Empatik Eğilim Ölçeğinin maddelerinin yaklaşık yarısı, bireylerin evet deme eğilimlerini önlemek için negatif yazılmıştır. Bireylerden her bir maddenin yanındaki 1'den 5'e kadar olan sayılardan birisini işaretleyerek, o maddedeki görüşe ne ölçüde katıldıklarını belirtmeleri istenmiștir. Bireylerin maddeleri okuduktan sonra işaretledikleri sayılar o maddeye ilişkin puanları oluşturmaktadır. Negatif yazılmış maddeler tersten puanlanmakta, "tamamen katılıyorum" cevabına 1, "hiç katılmıyorum" cevabına ise 5 puan verilmiştir. Testten alınabilecek en düşük puan; 1x20=20 iken, en yüksek puan ise $5 \times 20=100$ 'dür. Puanın yüksek olması, empatik eğilimin yüksek olduğu, düşük olması ise empatik eğilimin düşük olduğu anlamına gelmektedir. Empatik Eğilim Ölçeği, Dökmen (1988) tarafından 70 kişilik bir öğrenci grubuna üç hafta arayla iki defa uygulanmış, bu iki uygulamadan elde edilen testin tekrar güvenirlik katsayısı 0.82 olarak bulunmuştur. Testi yarılama yöntemiyle öğrencilerin ölçeğin tek ve çift maddelerinden aldıkları puanlar arasındaki korelasyon katsayısı ise 0.81 'dir. Bu araştırma kapsamında araştırmacı tarafından ölçeğin güvenirliği test tekrar test yöntemi ile incelenmiş, ölçek 100 kişilik bir öğrenci grubuna 15 gün ara ile uygulanmıştır. iki uygulamadan elde edilen puanlar arasındaki korelasyon 0.78 bulunmuştur. Geçerlik çalışması için Empati Eğilim Ölçeği ve Edwards Kişilik Tercih Envanteri’nin “Duyguları Anlama” bölümü arasındaki ilişkiye bakılmış ve 0.68 düzeyinde bir korelasyon bulunmuştur.

\section{Anketlerin Uygulanması}

Antrenman öncesi Empatik Eğilim Ölçeği sporculara, antrenörlerinden izin alınarak, uygulanmıştır.

\section{Veri Çözümü}

Araştırmada ölçek yoluyla toplanan verilerin analizi ve yorumu için bilgisayar ortamı kullanılmıştır. Sporcuların empatik eğilim puanları aritmetik ortalamalar $(\overline{\mathrm{x}})$ ve standart 
sapmalar (ss) kullanılarak betimlenmiştir. Verilerin dağılımının normal olmaması durumunda gurupların karşılaştırılmasında, Mann-Whitney U testi, dağılımın normal olduğu durumlarda İndependent- Samples $\mathrm{t}$-Testi grupların karşılaştırılmasında kullanılmıştır. Anlamlılık düzeyi çalışma öncesi $\mathrm{p}<0.05$ olarak belirlenmiştir.

\section{BULGULAR}

Bu bölümde araştırma ile ilgili bulgular sunulmuştur.

Tablo I. Çalışmaya Katılan Sporcuların Cinsiyetlerine Göre Empati Puan Ortalamaları

\begin{tabular}{cc}
\hline Takımlara Göre Cinsiyet Grupları & $\overline{\mathrm{x}} \pm \mathbf{s s}$ \\
\hline Takım Kadın (n:24) & $69.62 \pm 6.30$ \\
Bireysel Kadın (n:19) & $64.00 \pm 8.38$ \\
Takım Erkek (n:27) & $66.25 \pm 6.49$ \\
Bireysel Erkek (n:31) & $66.06 \pm 8.56$ \\
\hline
\end{tabular}

Tablo 1’e bakıldığında, takım sporlarıyla uğraşan kadın sporcuların, empatik eğilim puanları 69.62 \pm 6.30 , bireysel sporlarla uğraşan kadın sporcuların empatik eğilim puanları $64.00 \pm 8.38$, takım sporlarıyla uğraşan erkek sporcuların empatik eğilim puanları $66.25 \pm 6.49$, bireysel sporlarla uğraşan erkek sporcuların empatik eğilim puanları ise $66.06 \pm 8.56$ olarak ölçülmüştür. Puanlara bakılarak en yüksek empatik eğilim puanının takım sporlarıyla uğraşan kadın sporculara ait olduğu belirlenmiştir.

Tablo 2. Kadın Sporcuların Takım ve Bireysel Sporlara Göre Empati Puanlarının Karşılaştırılması

\begin{tabular}{ccccc}
\hline $\begin{array}{c}\text { Sporlara Göre } \\
\text { Kadın Sporcular }\end{array}$ & $\begin{array}{c}\text { Sıra } \\
\text { ortalaması }\end{array}$ & $\begin{array}{c}\text { Sıra } \\
\text { toplamı }\end{array}$ & Z & P değeri \\
\hline Takım Kadın (n:27) & 26.13 & 627 & -2.425 & 0.01 \\
Bireysel Kadın (n:19) & 16.19 & 319 & & \\
\hline
\end{tabular}

Tablo 2'de kadınların takım ve bireysel sporlara göre empatik eğilim puanları verilmektedir. Bu bulgulara göre, kadın sporcuların takım ve bireysel sporlardaki empatik eğilim puanları arasında anlamlı bir fark olduğu ortaya koyulmuştur $(\mathrm{Z}=-2.425, \mathrm{p}<0.05)$. 
Tablo 3. Erkek Sporcular Takım ve Bireysel Sporlara Göre Empati Puanlarının Karşılaştırılması

\begin{tabular}{ccccc}
\hline $\begin{array}{c}\text { Sporlara Göre } \\
\text { Erkek Sporcular }\end{array}$ & $\begin{array}{c}\text { Sıra } \\
\text { ortalaması }\end{array}$ & $\begin{array}{c}\text { Sıra } \\
\text { toplamı }\end{array}$ & $\mathbf{Z}$ & P değeri \\
\hline Takım Erkek (n:27) & 29.31 & 791.50 & & 0.93 \\
Bireysel Erkek (n:31) & 29.66 & 919.50 & -0.078 & \\
\hline
\end{tabular}

Tablo 3'e bakıldığında, erkek sporcuların takım sporları veya bireysel sporlarla uğraşmaları empatik eğilimlerini etkilememiştir. Takım sporlarıyla ve bireysel sporlarla uğraşan erkek sporcular arasında empatik eğilim açısından anlamlı bir fark olmadığı görülmüştür $(Z=-0.078$, $\mathrm{p}>0.05)$.

Tablo 4. Takım Sporlarıyla Uğraşan Sporcuların Cinsiyetlerine Göre Empati Puanlarının Karşılaştırılması

\begin{tabular}{ccccc}
\hline $\begin{array}{c}\text { Takımlara Sporlarına Göre } \\
\text { Cinsiyet Grupları }\end{array}$ & $\begin{array}{c}\text { Sıra } \\
\text { ortalaması }\end{array}$ & $\begin{array}{c}\text { Sıra } \\
\text { toplamı }\end{array}$ & Z & P değeri \\
\hline Takım Kadın (n:24) & 30.48 & 731.5 & & \\
Takım Erkek (n:27) & 22.02 & 594.5 & -2.035 & \\
\hline
\end{tabular}

Tablo 4'e göre, takım sporlarıyla uğraşan kadın ve erkek sporcuların empatik eğilim puanları arasında anlamlı bir fark olduğu görülmüştür $(Z=-2.035, \mathrm{p}<0.05)$.

Tablo 5. Bireysel Sporla Uğraşan Sporcuların Cinsiyetlerine Göre Empati Puanlarının Karşılaştırılması

\begin{tabular}{ccccc}
\hline $\begin{array}{c}\text { Bireysel Sporlara } \\
\text { Cinsiyet Grupları }\end{array}$ & $\begin{array}{c}\text { Sıra } \\
\text { ortalaması }\end{array}$ & $\begin{array}{c}\text { Sıra } \\
\text { toplamı }\end{array}$ & $\mathbf{Z}$ & P değeri \\
\hline Bireysel Kadın (n:19) & 22.82 & 433.5 & & 0.30 \\
Bireysel Erkek (n:31) & 27.15 & 841.5 & -1.021 & \\
\hline
\end{tabular}

Tablo 5’e bakıldığında, bireysel sporlarla uğraşan kadın ve erkek sporcuların empatik eğilim puanları arasında anlamlı bir fark olmadığ 1 görülmüştür $(\mathrm{Z}=-1.021, \mathrm{p}>0.05)$. 
Tablo 6. Cinsiyet Ayrımı Olmadan Takım ve Bireysel Sporların Empati Puanlarının Karşılaştırılması

\begin{tabular}{ccccc}
\hline $\begin{array}{c}\text { Takım ve Bireysel Sporcuların } \\
\text { Toplamı }\end{array}$ & $\overline{\mathrm{x}} \pm \mathbf{s s}$ & $\mathbf{t}$ & $\mathbf{d f}$ & P değeri \\
\hline Takım sporcuları (n:50) & $67.81 \pm 6.65$ & & & \\
Bireysel sporcular (n:51) & $65.40 \pm 8.35$ & & 0.11 \\
\hline
\end{tabular}

Tablo 6’ya incelendiğinde, takım sporları ile uğraşan sporcuların empatik eğilim puanları 67.81 \pm 6.65 , bireysel sporlarla uğraşan sporcuların empatik eğilim puanları ise $65.40 \pm 8.35$ olarak görülmektedir. Bu değerlerden ve p değerinden yola çıkarak, takım sporları ve bireysel sporlarla uğraşan sporcuların empatik eğilimleri arasında anlamlı bir fark olmadığı görülmektedir( $\mathrm{t}=1.598, \mathrm{p}>0.05)$.

Tablo 7. Çalışmaya Katılan Sporcuların Millilik Düzeylerine Göre Empati Puanlarının Karşılaştırılması

\begin{tabular}{ccccc}
\hline $\begin{array}{c}\text { Sporcuların Millilik } \\
\text { Düzeyleri }\end{array}$ & $\begin{array}{c}\text { Sıra } \\
\text { ortalaması }\end{array}$ & $\begin{array}{c}\text { Sıra } \\
\text { toplamı }\end{array}$ & Z & p değeri \\
\hline Milli sporcular (n:23) & 58.98 & 1356.50 & & 0.03 \\
Milli olmayan sporcular (n:73) & 47.28 & 3598.50 & -1.713 & \\
\hline
\end{tabular}

Tablo 7’ye bakıldığında sporcuların millilik düzeylerinin, sporcuların empatik eğilim puanları arasında fark yarattığı görülmektedir. Bu bulgulardan yola çıkarak millilik düzeyinin sporcuların empatik eğilimleri arasında anlamlı bir fark yarattığı görülmektedir $(Z=-1.713, p<0.05)$.

\section{Tartışma ve Sonuç}

Kadınların duygusal özelliklerinin erkekle göre daha üst düzeyde olduğu bilinmektedir. Böyle bir duygusallık, Tablo 1'de de görüldügü gibi, takım sporuyla birleşince yüksek bir empatik eğilim puan sonucunu ortaya çıkarmış olabilir. Dorak ve Vurgun (2006) farklı takım sporu yapan sporcuların empati düzeylerini cinsiyetler açısından karşılaştırdığında, kızların empati puan ortalamasını erkeklerden daha yüksek bulmuşlardır. Aydın’ın(1996) aktardığı bir çalışmada annelerin babalara, kızların ise erkeklere oranla daha fazla empati kurma becerisine sahip olduklarını belirtmiştir. Bu sonuçlara dayanarak cinsiyetin empatik eğilim puanlarında etkili olduğu söylenebilir. 
Tablo 2 incelendiğinde, takım sporuyla uğraşanların kadın sporcularının empatik eğilim puanlarının bireysel spor yapan kadın sporcuların empatik eğilim puanlarından daha fazla olduğu anlaşılmaktadır. Takım halinde yapılan antrenmanlarda ve müsabakalarda sporcular her zaman yan yanadırlar. Üzüntülerini, sevinçlerin her zaman birlikte paylaşırlar. Bu durum takım sporlarıyla uğraşan kadın sporcuların empatik eğilim puanlarını artırmış olabilir.

Takım ve bireysel spor yapan erkeklerin empatik eğilim puanları arasında istatistiksel bir fark olmadığı Tablo 3'te anlaşılmaktadır. Erkeklerin duygusal olmadıkları bilinmektedir. Yapılan araştırmada erkeklerin empatik eğilim puanlarının takım veya bireysel spor branşlarına göre farklılık göstermemesinin nedeni, erkeklerin duygusal anlamda bağ kurmaktan uzak olmaları olabilir.

Tablo 4 incelendiğinde şu söylenebilir: Kadınların empatik eğilim düzeylerinin erkeklerden daha yüksek olduğu bilinmektedir. Bu bilgiye göre, takım sporlarıyla uğraşan kadın sporcuların erkek sporculardan daha yüksek empatik eğilim puanına sahip olmalarının normal olduğu düşünülebilir.

Tablo 5 sonuçlarına göre, cinsiyet farkı empatik eğilim puanlarında etkili olmamıştır. Anlamlı bir fark oluşumunu engelleyen faktör ise takım sporlarıyla uğraşan sporcuların empatik eğilim puanlarının daha yüksek olması olabilir. Akçakoyun ve arkadaşlarının(2010) yapmış olduğu Dövüş ve Takım Sporcularının Empati Düzeylerinin Karşılaştırılması isimli çalışmasında da benzer sonuçlara rastlanmıştır.

Tablo 6'daki bulgular göz önüne alındığında, sporcuları takım sporları veya bireysel sporlarla uğraşmaları empatik eğilim puanlarını etkilemediği anlaşılmaktadır. Takım sporlarıyla uğraşan kadın sporcuların empatik eğilim puanlarının yüksek olduğu diğer bulgularda yer almıştı, ancak bu tabloda takım ve bireysel sporlarıyla uğraşan sporcularının empatik puanları arasında fark çıkmaması erkek sporcuların empatik eğilim puanlarının da burada yer almasından kaynaklaniyor olabilir.

Tablo 7’ye göre millilik statüsü sporcuların empatik eğilim puanlarını etkilemiştir. Millilik statüsünün sporun zirvesi olduğu kabul edilirse, spor ahlakı ve sporculuk karakteri yerleşmiş sporcuların empatik eğilim puan düzeylerinin daha yüksek olması beklenir. Milli sporcuların empatik eğilim puanlarının yüksekliğini spor kültürleri, spor çevreleri ve spor yaşlarının etkilemiş olabileceği düşünülebilir.

\section{SONUÇ ve ÖNERILER}

Sonuç olarak, takım sporcuları ve bireysel sporcular arasında empatik eğilim puanları arasında istatistiksel bir fark bulunamamıştır; sporcuların millilik düzeyleri empatik eğilim puanları açısından istatistiksel bir fark yaratmıştır; cinsiyet, takım sporcularında empatik eğilim puanlarını etkileyen bir değişken olup, empatik eğilim puanları arasında anlamlı bir fark yaratmıştır; takım sporları ve bireysel sporlarla uğraşmak erkek sporcuların empatik eğilim puanları arasında anlamlı bir fark oluşturmamıştır. 


\section{KAYNAKLAR}

Akçakoyun F., Çalışkan E., Karlı H. (2010). Dövüş ve Takım Sporcularının Empati Düzeylerinin Karşılaştırılması, Türkiye Kickboks Federasyonu Spor Bilimleri Dergisi, 3(2), 37-47

Aydın A. (1996). Empatik Becerinin Çeşitli Değişkenler Açısından İncelenmesi, Ege Üniversitesi Sağlık Bilimleri Enstitüsü Yüksek Lisans Tezi, İzmir.

Balçıkanlı G. S., Yıldıran İ. (2011). Profesyonel Futbolcuların Sportmenlik Yönelimleri ve Empatik Eğilim Düzeyleri, Spormetre Beden Eğitimi ve Spor Bilimleri Dergisi, IX (2), 49-56

Bayam G., Şimşek E. U., Dilbaz N. (1993). Üç Farklı Meslek Grubunda Empatik Beceri Düzeylerinin Karşılaştırılması, Kriz Dergisi. 3 (1-2),182-184.

Berger D. (1984). On the Way to Empathic Understanding. American Journal of Psychotherapy. 28(1),111119.

Bredemeier B., Weiss M., Shields D., Cooper B. (1986). The Relationship of Sport Involvement with Children's Moral Reasoning and Aggression Tendencies, Journal of Sport Psychology, 8(4), 304318

Bredemeier JBL. (1994). Children's Moral Reasoning and Their Assertive, Aggressive, and Submissive Tendencies in Sport and DailyLife, Journal of Sport \& Exercise Psychology, 16(1), 1-14

Bredemeier JB., Shields D. (1986). Moral Growth Among Athletes and Nonathletes: A Comparative Analysis, The Journal of GeneticPsychology, 147(1), 7-18

Çetin Ü. F. (2010). Ortaöğretim Düzeyi Gençlerde Dindarlık Empati İlişkisi, Yüksek Lisans Tezi, Süleyman Demirel Üniversitesi Felsefe ve Din Bilimleri Anabilim Dalı, Isparta

Çıdam K. (1996). Televizyon ve Spor "Spor ve Spor Magazin Programlarında Erotizm ve Şiddet, Anadolu Üniversitesi Sosyal Bilimler Enstitüsü, Yüksek Lisans Tezi, Eskişehir

Davis HM. (1980). A Multidimensional Approach to Individual Differences in Empathy, JSAS Catolog of Selected Documents in Psychology, 10, 85

Davis HM. (1983). Measuring Individual Differences in Empathy: Evidence for a Multidimensional Approach, Journal of Personality andSocial Psychology, 44(1), 113-126

Dorak F., Vurgun N. (2006). Takım Sporları Açısından Empati ve Takım Birlikteliği İlişkisi. Spormetre Beden Eğitimi ve Spor Bilimleri Dergisi, 2(2006) 73-77

Dökmen Ü. (1988). Empatinin Yeni Bir Modele Dayanılarak Ölçülmesi ve Psikodrama ile Geliştirilmesi. Ankara Üniversitesi Eğitim Bilimleri Fakültesi Dergisi, 21(1988), 155-190.

Eisenberg N., Holmgren AR., Fabes AR. (1998). The Relation of Children's Situational Empathy-Related Emotions to DispositionalProsocial Behavior, International Journal of Behavioral Development, 22(1), 169-193

Eisenberg N., Miller PA. (1987). The Relation of Empathy to Prosocial and Related Behaviors, Psychological Bulletin,101, 91-119

Gano-Overway LA., Guivernau M., Magyar MT. Waldro, JJ., Ewing ME. (2005). Achievement Goal Perspectives, Perceptions of theMotivational Climate, and Sportspersonship:İndividual and Team Effects, Psychology of Sport and Exercise, 6(2), 215-232

Hoffman ML. (1990). The Contribution of Empathy to Justice and Moral Judgment, In: Esinberg N, Strayer J. (Editors), Empathy and ItsDevelopment, Cambridge University Press, 47-80, New York

Jones C., Mcnamee M. (2000). Moral Reasoning, Moral Action, and the Moral Atmosphere of Sport, Sport, Education and Society, 5(2), 131-146

Kavussanu M. (2006). Motivational Predictors of Prosocial and Antisocial Behaviour in Football, Journal of Sport Science, 24(6), 575-588

Kavussanu M., Seal AR., Phillips DR. (2006). Observed Prosocial an Antisocial Behaviours in Male Soccer 
Teams: Age Differences Across Adolescense and the Role of Motivational Variables, Journal of Applied Sport Psychology, 18(4), 326-344

Kavussanu M., Stamp R., Slade G., Ring C. (2009). Observed Prosocial and Antisocial Behaviors in Male and Female Soccer Players, Journal of Applied Sport Psychology, 21 (Supp. 1), 62-76,

Lemyre PN., Roberts GC. Ommundsen Y. (2002). Achievement Goal Orientations, Perceived Ability, and Sportspersonship in YouthSoccer, Journal of Applied Sport Psychology, 14(2), 120-136

Mehrabian A., Epstein N. (1972). A Mesaure of Emotional Empathy, Journal of Personality, 40(4), 525-543

Stornes T., Ommundsen Y. (2004). Achievement Goals, Motivational Climate and Sportspersonship: a Study of Yound HandballPlayers, Scandinavian Journal of Education, 48(2), 205-221

Vallerand RJ., Briere NM., Blanchard C., Provencher P. (1997). Development and Validation of the Multidimensional SportspersonshipOrientations Scale, Journal of Sport \& Exercise Psychology, 19(2), 197-206

Yılmaz İ., Akyel Y. (2008). Beden Eğitimi Öğretmen Adaylarının Empatik Eğilim Düzeylerinin Çeşitli Değişkenler Açısından İncelenmesi, Ahi Evran Üniversitesi Kırşehir Eğitim Fakültesi Dergisi (KEFAD), 9(3), 27-33

Yıldız D. (1979).Türk Futbol Tarihi. İstanbul: Eko Matbaası 